\title{
EDITORIAL
}

\section{Medical Geology - A Futuristic Scientific Discipline}

The discipline of geology is best known for the scientific study of rocks, minerals, mining of ore deposits, physical features of the earth such as mountains and activities of the interior of the earth including earthquakes and volcanic eruptions. The tendency for some researchers to be highly discipline oriented and working in their self made "isolated compartments" pertaining to their own subject has produced less information on the true nature of the earth and its complex processes. In order to obtain a better understanding of these intricate interactions, the artificial boundaries between the so called "disciplines" has to be broken down and a true multidisciplinary approach established. The extreme value of multidisciplinary science stems from the fact that to all intents and purposes, the earth is a closed system and the multitude of complex physical and chemical interactions cross all spheres within the earth as exemplified by the lithosphere, hydrosphere, atmosphere and biosphere.

Geology which hitherto had placed great emphasis on rocks, minerals and the physical features will therefore interact with the biosphere which includes plants, animals and humans as well. Chemical cycles do not stop at any manmade boundary but pass imperceptibly into other domains and the geo-bio interactions must therefore have a significant impact on the health of humans and animals.

It was only recently realized that geogenic processes could well have a marked influence on certain aspects of human and animal health and the new discipline "Medical Geology" emerged (Dissanayake and Chandrajith, 1999; Selinus et al., 2009; Selinus and Finkelman, 2011). In several countries, notably China, India and Sri Lanka among others mostly in the tropical belt, it had been observed that certain specific geographic areas on which large populations live, have some widespread diseases which were not prevalent in other areas and interestingly even in a few neighbouring regions. This clearly indicated a geogenic factor that was probably the cause of the disease when other factors such as food habits, lifestyles are excluded. In nearly all these cases, the people had identical food habits and lived a very similar life.

For example, in China, two diseases, Keshan's Disease (KD) and Kashin-Beck Disease (KBD) were particularly prevalent in some areas. It was observed that selenium was found in very low concentrations in soils in these parts, resulting in the health issues mentioned above. Considering the fact that China has over $20 \%$ of the global population, these selenium deficiency diseases were of major concern. This resulted in geochemical mapping of the country and the maps produced clearly showed areas where certain chemical elements were either in excess or deficient. The arsenic problem in Bangladesh and west Bengal also had their origin in the geological environment of arseniferous sediments in the major rivers. The discovery of the "low selenium belt" of China also known as the "disease belt" is a direct result of the work carried out by teams of medical geologists and this paved the way for other countries to follow suit.

Sri Lanka, through the pioneering research work carried out by the Department of Geology, University of Peradeniya has contributed significantly to the development of Medical 
Geology, notably the discovery of the "fluoride belt" in the dry zone where fluoride was found in excessive concentrations in the groundwater in large areas of the north central regions, Uva and extending towards the deep south (Dissanayake and Weerasooriya, 1985). This belt coincided with a very high incidence of dental and skeletal fluorosis, the former in large numbers of school children. Subsequent updating of the groundwater fluoride map of Sri Lanka (Chandrajith et al., 2012), showed new areas with high fluoride levels. Further, the chronic kidney disease of unknown etiology (CKDu) also coincides with the fluoride belt and Dissanayake (2005) first suggested that groundwater fluoride may have a strong link with the etiology of CKDu. Recent research now points to fluoride as a geochemical carrier of the probable causative species particularly in water. Interestingly, the geochemistry of the groundwater in the disease prone areas is highly conducive to the formation of apatite (a calcium hydroxy/fluoro phosphate mineral) in the kidney tubules which could plug them resulting in the malfunction of the kidney. Micronephrocalcinosis involving apatite formation may well prove to be an important factor in future research pertaining to $\mathrm{CKDu}$. The basic fact is that in many less affluent countries, particularly in the tropical belt, millions of people live in intimate contact with the immediate physical environment comprising of rocks, soils, minerals and water obtaining their water and food from it. It is highly logical therefore to assume that the geochemistry of the habitat will, most certainly, have an impact on their general health depending on the deficiencies and excesses of essential and toxic chemical species. The pathways of these species find their way quite easily into the human body via the geo-bio barrier as clearly illustrated by the case of fluoride in drinking water.

Similarly, other studies related to the low abundance of iodine, notably in mountainous regions resulting in Iodine Deficiency Diseases (IDD), nitrates in water causing cancer and metheamoglobinemia, water hardness with a high $\mathrm{Ca} / \mathrm{Mg}$ ratio and cardiovascular diseases are also now being studied in several countries. Interestingly, the mineral magnetite, best known to geologists, has been observed in the human brain (Kirschivink et al., 1999), while the mineral apatite is known to play a major role in the clogging of human arteries (Louvet et al., 2015). Mineralogy is finding its way into human physiology and biomineralogy will be closely associated with medical geology in the future.

Sri Lanka has been in the forefront of research in the emerging field of medical geology mainly through the work of Dissanayake and Chandrajith (1999), Dissanayake (2005a) and Dissanayake (2005b). The publication of the book "Introduction to Medical Geology- focus on tropical environments" published by Springer is the first of its kind and has attracted global attention on the new discipline and it is indeed heartening to note that the book is listed as a text book in universities in U.S.A, India and Iran among other countries. A geochemical atlas showing the distribution of chemical species in groundwater or soil is a national need for any country and the first Hydrogeochemical Atlas of Sri Lanka (Dissanayake and Weerasooriya, 1985), has greatly benefitted researchers in several disciplines including dental and medical experts.

With the development of advanced analytical instrumentation, such a ICP-MS, new software, GPS and GIS systems, geochemical mapping will in the future yield a wealth of very accurate information and even research on Mars and objects in space will benefit enormously from these developments in medical geology. Further, such data gathered from geochemical mapping will almost certainly contribute to the better understanding of the diseases now classified as "diseases of unknown etiology". 


\section{REFERENCES}

Chandrajith, R., Padmasiri, J.P., Dissanayake, C.B and Prematilaka, W. (2005) Spatial distribution of fluoride in groundwater of Sri Lanka. Journal of the National Science Foundation, Sri Lanka. 40(4):303-309.

Dissanayake, C.B (1991 The fluoride problem in the groundwater of Sri Lanka. Environmental management and health. Int. J. Environmental Studies .38(2-3) :137-155.

Dissanayake, C.B (2005a). Of stones and health. Medical Geology in Sri Lanka. Science. 5736883-885.

Dissanayake, C.B (2005b). Water quality in the dry zone of Sri Lanka - some interesting health aspects. Journal of the National Science Foundation. Sri Lanka. 33(3):161-168.

Dissanayake, C.B and Chandrajith, R (1999). Medical geochemistry of tropical environments. Earth Science Reviews (Elsevier) 47:219-258.
Dissanayake, C.B and Weerasooriya, S.V.R (1985). The Hydrogeochemical Atlas of Sri Lanka. Publication of the Natural Resources, Energy and Science Authority of Sri Lanka. 103 pp.

Dissanayake, C.B and Chandrajith, R (2009). Introduction to Medical Geology (Springer). 297 pp.

Kirschivink, J.L., Kobayashi, A and Woodford, B.J (1999). Magnetite biomineralization in the human brain. Proc. National Academy of Sciences, U.S.A 84:16 7683-7.

Louvet, L., Bazin,D.,Buchel, J.,Steppan, S,Deetjen,J.P and Massy, Z.A (2915). Characterization of calcium phosphate crystals in calcified human aortic vascular smooth muscle cells and potential role of magnesium. PLOS/one 10(1):e0115342.

Selinus, O and Finkelman, R.B (2011). Geochemical aspects of medical geology (invited paper). J. Geological Society of Sri Lanka. (Vidya Jyothi C.B. Dissanayake Felicitation volume.) 14:01-09.

Selinus, O (Ed) (2005). Essentials of Medical Geology. Academic Press. 812 pp.

C.B. Dissanayake 